\title{
Multidimensional Poverty of Children in Mozambique
}

Kristi Mahrt ${ }^{1} \cdot$ Andrea Rossi $^{2} \cdot$ Vincenzo Salvucci $^{3} \cdot$ Finn Tarp $^{3,4}$

Accepted: 22 October 2019/Published online: 10 March 2020

(C) UNU-WIDER 2020, corrected publication 2020

\begin{abstract}
We analyse the multidimensional wellbeing of children aged 0-17 in Mozambique and find that $46.3 \%$ can be considered multidimensionally poor. A substantial divide exists between urban and rural areas and between northern and southern provinces. We compare Mozambican children's wellbeing with that of children in other regional countries. Despite impressive gains in some indicators, multidimensional child poverty in Mozambique still substantially exceeds that in neighbouring countries. Targeted policies considering the specificities of child welfare are needed to ensure that the national-level growth and poverty reduction experienced by the population as a whole translate into better living conditions for children.
\end{abstract}

Keywords Multidimensional poverty · Children · Child wellbeing · Mozambique

JEL Classification I32 $\cdot$ J13

Vincenzo Salvucci

vincenzo.salvucci@gmail.com

Kristi Mahrt

k.mahrt@cgiar.org

Andrea Rossi

arossi@unicef.org

Finn Tarp

finn.tarp@econ.ku.dk

1 IFPRI, Washington, DC, USA

2 UNICEF East Asia and Pacific Regional Office, Bangkok, Thailand

3 University of Copenhagen, Copenhagen, Denmark

4 UNU-WIDER, Helsinki, Finland 


\section{Introduction}

Child poverty is overwhelming in the developing world, especially in Sub-Saharan Africa and South Asia. Regarding consumption poverty, Save the Children (2016) estimates that about 570 million children live in extreme monetary poverty (less than $\$ 1.25$ a day) worldwide. Recent estimates by Alkire et al. (2017) suggest that the multidimensional poverty status of children might even be worse: not only about half of all multidimensionally poor people are children - i.e. about 689 million people $^{1}$-, but $87 \%$ of them live in just two regions, South Asia and Sub-Saharan Africa. ${ }^{2}$ Mozambique is among the poorest countries in Africa and in the world, not just in terms of GDP per capita, but also with respect to the Human Development Index and to the Global Multidimensional Poverty Index (UNDP 2018; UNDP and OPHI 2019). Nonetheless, the more than 20-year period following the end of war in Mozambique has been marked by periods of rapid growth and broad-based reduction in multidimensional and consumption poverty. Arndt et al. (2016), DEEF (2016), Arndt et al. (2017) and Baez Ramirez et al. (2018) present a comprehensive review of this progress. In particular, at the national level, consumption poverty has decreased by about 5 percentage points and welfare levels have improved with respect to 2008/09; moreover, comparing 2014/15 levels with the very low welfare levels observed in 1996/97, it emerges clearly that the consumption poverty reduction and the gains in well-being have been substantial, in both rural and urban zones and in every province (DEEF 2016). ${ }^{3}$

Though the situation of Mozambican children has also improved, evidence suggests that indicators particularly relevant to children may be more resistant to advancement (see also Sahn and Alderman 1997; Azzarri et al. 2011; Castigo and Salvucci 2017; Ferrone et al. 2019; Pomati and Nandy 2019). Indeed, some of the indicators that are more relevant to child welfare are either found to move very slowly or greatly depend on previous improvements in other household or community indicators. Some others depend on attitudes that are rooted in their cultural contexts (Jain and Kurz 2007; UNFPA 2012; UNICEF and UNFPA 2018). These reasons reinforce the argument for the production of a child-specific poverty index (see also de Milliano and Plavgo 2018).

Previous analyses of multidimensional child welfare based on Mozambican household data have been carried out by UNICEF and other researchers, showing mixed evidence of improvement. UNICEF analysis of deprivation-based child poverty in 2003 and 2008 indicates that significant improvements in severe health, nutrition,

\footnotetext{
${ }^{1}$ Save the Children (2016) estimates a slightly higher number of poor children from the multidimensional point of view, 750 million children.

${ }^{2}$ They estimate that the number of poor children is roughly equal in each region, and that about half of South Asia's children and two-thirds of Sub-Saharan children can be considered multidimensionally poor (Alkire et al. 2017). This is also in line with recent estimations for Sub-Saharan Africa by de Milliano and Plavgo (2018).

${ }^{3}$ The consumption poverty headcount has fallen by about 25 percentage points and the percentage of people living in a household characterized by six contemporaneous deprivations (not one member having completed first level primary school, no access to safe water, inadequate sanitation, grass roofing, no electricity, and very limited possession of durable goods) went down from about half to less than $15 \%$ of the population (DEEF 2016).
} 
and education deprivations were tempered by deteriorating access to safe water ${ }^{4}$ (UNICEF 2006, 2011). Deprivation-based poverty - the percentage of children experiencing deprivation in two or more indicators - remained high at $49 \%$, despite an 11-point reduction between 2003 and 2008. Arndt et al. (2012) confirm these findings with an alternative approach to multidimensional welfare measurement based on first-order dominance (FOD). Applying this approach to 2003 Demographic and Health Survey (DHS) and 2008 Multiple Indicator Cluster Surveys (MICS) data in the dimensions of water, sanitation, shelter, education, and information, FOD suggests that welfare for children aged 7-17 essentially stagnated between 2003 and 2008, with gains only evident in a couple of provinces. They also find that spatial inequality did not decrease. Taking advantage of the most recent full-fledged DHS data available for Mozambique - the DHS 2011 -, UNICEF's situation analysis of Mozambican children (UNICEF 2014) and MISAU et al. (2013) find that between 2008 and 2011, chronic under-nutrition (stunting) of children under five remained virtually unchanged at one of the highest levels in the world $(43 \%) .^{5}$ Access to improved water and sanitation both increased during this period. However, in contrast to earlier progress, primary school enrolment and completion declined between 2008 and 2011 (UNICEF 2014). The more recent and extremely rich 2014/15 Mozambique household budget survey, Inquérito aos Agregados Familiares sobre Orçamento Familiar (IOF; see DEEF 2016; INE 2015), thus provides a salient opportunity to reassess the welfare of Mozambican children across a vast array of dimensions.

The purpose of this analysis is thus to first estimate multidimensional child poverty of Mozambican children using a broad set of welfare indicators made available by more recent databases; and second to examine urban/rural, regional, gender, and age disparities in child multidimensional welfare, using the Alkire-Foster (AF) methodology. ${ }^{6}$ It includes an examination of child welfare indicators and the contribution of the different welfare dimensions to child multidimensional poverty. The relationship between multidimensional and consumption poverty at aggregate and individual levels is also considered.

Moreover, we also aim to provide a regional context over time, comparing the wellbeing situation and trends of Mozambican children to those of children in four neighbouring countries: Malawi, Tanzania, Zambia, and Zimbabwe. International comparisons are conducted using compatible DHS data from two recent time periods.

Our main hypothesis is that the welfare situation of children needs to be assessed using child-specific indicators and dimensions, because the standard welfare characteristics used to assess the welfare situation of the entire population of a country might overlook important characteristics that critically influence the well-being of kids aged 0 to 17 years (see also Save the Children 2016; Alkire et al. 2017; de Milliano and Plavgo

\footnotetext{
${ }^{4}$ Differently from other studies, in this analysis unsafe water is defined to be either surface water or water more than $30 \mathrm{~min}$ from the home.

${ }^{5}$ Furthermore, Cardoso et al. (2016a) highlight that chronic malnutrition appears to be strictly linked to household wealth, mother's education, area of residence, and access to safe water and improved sanitation facilities, and that the relative importance of these variables remained mostly unchanged between 2003 and 2011.

${ }^{6}$ A related analysis, by Ferrone et al. (2019), implemented the Multiple Overlapping Deprivation Analysis (MODA) methodology on the same set of data, finding complementary results. The present analysis and the one by Ferrone et al. (2019) have been developed in coordination with UNICEF-Mozambique.
} 
2018; Ferrone et al. 2019). Moreover, including age-specific characteristics greatly enriches the chance of grasping specific deprivations suffered by children at different stages of growth. At the same time, we do not expect the multidimensional poverty index results to be extremely different from the estimates for the entire population. Indeed, Mozambique is among the poorest countries in Sub-Saharan Africa, but also among those that are growing most rapidly within the region, so we presume that the welfare situation of children also improved in recent years - even if at a different pace depending on the region and area of residence -, closely following the progress registered for the population as a whole. ${ }^{7}$ Nonetheless, we believe that including a series of additional characteristics, and allowing these characteristics to have a different relative importance with respect to age groups, may offer a more complete picture of the different deprivations suffered by Mozambican children and provide policy makers and institutions concerned specifically with child well-being with a reference tool for future analyses in this area and with supplementary elements that could support the design of better targeted age- and region-specific policies. The paper proceeds as follows: Section 2 briefly describes the AF methodology. Section 3 presents an analysis of multidimensional poverty in Mozambique. Section 4 provides DHS-based international comparison. Section 5 discusses the main results and limitations of the study, while Section 6 concludes.

\section{Methodology: The Alkire-Foster Approach}

The Alkire-Foster approach developed by Alkire and Foster (2007) is well known for its application in the assessment of multidimensional poverty in developing countries worldwide, and especially in the United Nations Development Programme (UNDP) Multidimensional Poverty Index (MPI), which assesses welfare in over one hundred countries (see, for example, Alkire and Santos 2010). This method has the advantage of being simple and intuitive as well as directly relevant to policy goals relating to specific welfare dimensions. This section provides a brief overview of the methodology. Alkire et al. (2015) provide a recent and comprehensive discussion of an array of multidimensional poverty measures.

The AF approach aggregates individual welfare outcomes across multiple dimensions into a single index that reflects both the incidence and the intensity of multidimensional poverty. The index is created in two steps: identification and aggregation. A dual cut-off method first applies dimension-specific thresholds to identify individual deprivation in each dimension. An across-dimension cut-off $(k)$ then distinguishes the multidimensionally poor from the non-poor; those with a weighted deprivation count which is greater than $k$ are deemed poor. Poverty incidence $(H)$ is a headcount measure of the percentage of individuals or households identified as multidimensionally poor. The headcount ratio cannot fully reflect changes in multidimensional poverty because it does not capture changes in the number of deprivations faced by the poor. Therefore, poverty intensity $(A)$ is incorporated to measure the average weighted deprivation count among those who are identified as multidimensionally poor. The final AF poverty

\footnotetext{
${ }^{7}$ For multidimensional poverty estimates relative to the entire Mozambican population, see for example Cardoso et al. (2016b), DEEF (2016), OPHI (2017).
} 
index, $M_{0}$, is expressed as the product of the incidence and the intensity of poverty, $M_{0}=H A$.

\section{Multidimensional Poverty in Mozambique}

In this section we first present the indicators and data used for the analysis of child deprivation, followed by a detailed description of deprivation with respect to individual welfare indicators, at different geographical levels, for girls and boys and for different age categories. In Subsection 3.3, various multidimensional poverty results are presented, together with the contribution of specific welfare dimensions to the poverty index; an analysis of the relation between multidimensional and consumption poverty estimates at various levels follows.

\subsection{Indicators and Data}

The primary purpose of this analysis is to assess the current situation of children in Mozambique based on the 2014/15 IOF. To target aspects of wellbeing most relevant in distinct stages of a child's life, we consider three populations of children, aged $0-4,5-12$, and 13-17. Welfare outcomes considered in this study evolved from a 2016 workshop, hosted by UNICEF in Maputo, where participants were engaged in determining what constitutes a deprivation for a Mozambican child. Deprivations are categorized in eight dimensions: family; nutrition; child labour; education; health; water, sanitation, and hygiene (WASH); participation; and housing. Within each dimension one or more indicators were defined to measure dimensional deprivation. ${ }^{8}$ Ultimately, deprivation indicator choices and the associated thresholds differentiating between deprived and not deprived are rooted in both critical aspects of child wellbeing in Mozambique and the availability of information in the 2014/15 IOF. Indicator weights were assigned by age group such that each dimension is given equal weight and, within dimensions, each indicator is given equal weight. The resulting indicators and weights are presented in Table 1.

The 2014/15 IOF was conducted by the Mozambican National Statistics Institute (INE) and provides information on daily, monthly, and yearly consumption expenditures, housing characteristics, health status, education, and employment. The data are representative at the national, urban/rural, regional, and provincial levels. The 2014/15 IOF was conducted as a panel survey with each household interviewed in three quarters. However, most household welfare data that are used in the current analysis of multidimensional wellbeing were only released for the

\footnotetext{
${ }^{8}$ See also Ferrone et al. (2019) for a more detailed description of the outcome of the workshop organized by UNICEF Mozambique in Maputo in August 2016. Participants discussed about what constitutes a deprivation in the Mozambican context, which indicators are more important and how they can be grouped into deprivation dimensions. It emerged that some of the dimensions that were felt as important could not be adequately measured at the time, for example the dimensions of Security (protection from physical violence), Participation (the ability of children to participate in decisions) and Leisure. Participants also discussed about the determinants and correlates of the various deprivation indicators and dimensions, providing precious inputs for future work in this direction.
} 
Table 1 IOF deprivation indicators

\begin{tabular}{|c|c|c|c|c|c|}
\hline \multirow[t]{2}{*}{ Dimension } & \multirow[t]{2}{*}{ Indicator } & \multirow[t]{2}{*}{ Threshold } & \multicolumn{3}{|c|}{ Weight by age group } \\
\hline & & & $0-4$ & $5-12$ & $13-17$ \\
\hline \multirow[t]{2}{*}{ Family } & Parents & At least one parent dead & $(1 / 6)$ & $(1 / 7)$ & \\
\hline & Marriage & $\begin{array}{l}\text { Child ever married or in } \\
\text { a marital union }\end{array}$ & & & $(1 / 7)$ \\
\hline \multirow[t]{3}{*}{ Nutrition } & Stunting & $\begin{array}{l}\text { Height for age less than }-2 \\
\text { standard deviation from } \\
\text { WHO reference }\end{array}$ & $(1 / 18)$ & & \\
\hline & Underweight & $\begin{array}{l}\text { Weight for age less than }-2 \\
\text { standard deviation from } \\
\text { WHO reference }\end{array}$ & $(1 / 18)$ & & \\
\hline & Wasting & $\begin{array}{l}\text { Weight for height for age less } \\
\text { than }-2 \text { standard deviation } \\
\text { from WHO reference }\end{array}$ & $(1 / 18)$ & & \\
\hline \multirow[t]{2}{*}{ Education } & Enrolment & Did not attend school in the last year & & $(1 / 7)$ & \\
\hline & Primary & $\begin{array}{l}\text { Did not complete primary two } \\
\text { (seven years) }\end{array}$ & & & $(1 / 7)$ \\
\hline Child labour & Child labour & $\begin{array}{l}\text { Engages in child labour according to } \\
\text { UNICEF/International Labour } \\
\text { Organisation definition (UNICEF 2013) }\end{array}$ & & $(1 / 7)$ & $(1 / 7)$ \\
\hline \multirow[t]{2}{*}{ Health } & Bed net & Did not sleep under a bed net & $(1 / 12)$ & & \\
\hline & $\begin{array}{l}\text { Distance to health } \\
\text { facility }\end{array}$ & More than $30 \mathrm{~min}$ to nearest health facility & $(1 / 12)$ & $(1 / 7)$ & $(1 / 7)$ \\
\hline \multirow[t]{3}{*}{ WASH } & Water & Unimproved source of drinking water & $(1 / 18)$ & $(1 / 21)$ & $(1 / 21)$ \\
\hline & Distance to water & More than $30 \mathrm{~min}$ to water source & $(1 / 18)$ & $(1 / 21)$ & $(1 / 21)$ \\
\hline & Sanitation & Unimproved sanitation type & $(1 / 18)$ & $(1 / 21)$ & $(1 / 21)$ \\
\hline Participation & Information & $\begin{array}{l}\text { No information device (TV, radio, any } \\
\text { phone, or computer) }\end{array}$ & $(1 / 6)$ & $(1 / 7)$ & $(1 / 7)$ \\
\hline \multirow[t]{3}{*}{ Housing } & Crowding & More than four people per room & $(1 / 18)$ & $(1 / 21)$ & $(1 / 21)$ \\
\hline & Floor and roof & Both floor and roof of primitive materials & $(1 / 18)$ & $(1 / 21)$ & $(1 / 21)$ \\
\hline & Electricity & $\begin{array}{l}\text { Primary energy source for lighting is not } \\
\text { electricity }\end{array}$ & $(1 / 18)$ & $(1 / 21)$ & $(1 / 21)$ \\
\hline
\end{tabular}

Source: Authors' elaboration

first quarter and therefore the present analysis is restricted to this period (August to November 2014). ${ }^{9}$ The first-quarter survey includes 30,924 children aged 0-17. For further details regarding the 2014/15 IOF please refer to DEEF (2016) and INE (2015).

The AF methodology determines multidimensional poverty by comparing the children's weighted deprivation count with a poverty cut-off, which in this analysis

\footnotetext{
${ }^{9}$ It is likely that certain indicators such as underweight, wasting, child labour, and bed net usage could vary by season. 
is set to $k=1 / 3$. The cut-off of one-third is commonly chosen in the literature, including the 2016 Global MPI (Alkire and Robles 2016) and the 2017 Mozambique MPI (OPHI 2017). The AF methodology requires that the sample be restricted to children with non-missing values for all indicators considered for their age group. Though in most cases missing values are scarce, anthropometric and child labour data are an exception. All children are eligible to be measured in the IOF; however, $17 \%$ of the under-5 sample are dropped because either children were not actually measured or the measurements were infeasible. ${ }^{10}$ To a lesser degree, labour data for children aged 5-17 are often missing, and as a result $4 \%$ of the 5-12 and the 13-17 samples are dropped.

\subsection{Deprivation Rates}

Table 2 presents deprivations in each indicator by relevant age ranges. ${ }^{11}$ Overall, deprivation is substantially higher in rural than urban areas and increases moving from the south to the north. The parent indicator follows the opposite pattern, but showing a limited degree of variation, with rural and northern children facing somewhat lower deprivation rates. Nearly three-quarters of all children are deprived in sanitation and electricity and more than two-thirds of Mozambican teens have not completed primary school. The rural-urban gap is profound and particularly striking in household indicators. For instance, $54 \%$ of rural children do not have access to a safe drinking water source, compared with only $13 \%$ of urban children.

Concerning deprivation rates by sex, girls outperform boys in nearly all indicators except for marriage and, to a small degree, wasting (Table 10 in the Appendix). The marriage rate for boys is less than $2 \%$ in all areas, compared with more than $11 \%$ for girls nationally. This disparity is even greater in rural areas and the north, where marriage rates for girls are double those of urban and southern areas (14.1 versus $6.7 \%$ and 13.9 versus 7.3 , respectively). Boys experience considerably higher deprivation rates in stunting in all regions (nationally, $47 \%$ compared with $38 \%$ among girls). ${ }^{12}$ Interestingly, girls' advantage in the primary completion indicator is greatest in urban areas (43.4\%) and the south (37.7\%), where the deprivation gap is approximately 4 and 10 percentage points, respectively.

Using previous household budget surveys, we calculated deprivation rates for indicators that could be consistently defined over time using the same underlying assumptions. Table 3 provides mixed evidence of improved child welfare since the first household survey was conducted in 1996. While most indicators have steadily declined, child marriage and stunting have improved only modestly. Though both enrolment and crowding initially improved, deprivation rates deteriorated in 2014/15.

\footnotetext{
${ }^{10}$ Children aged 0-4 who are missing anthropometric data and children aged $12-17$ who are missing labour data are poorer than their counterparts. Of children missing anthropometric data, $55.5 \%$ are poor compared to $49.3 \%$ with complete data. Similarly, $56.2 \%$ of children missing labour data are poor compared to $48.0 \%$ of children with complete data. The non-random nature of the subsamples with non-missing values might cause our multidimensional poverty estimates to underestimate multidimensional poverty in the country.

${ }^{11}$ For consistency with official figures, descriptive statistics presented in this section are based on the full sample of children, which includes children with missing values in one or more indicators.

12 This confirms previous findings for Mozambique by Azzarri et al. (2011), Cardoso et al. (2016a) and Salvucci (2016).
} 
Table 2 Deprivation rates by indicator and area

\begin{tabular}{|c|c|c|c|c|c|c|c|c|}
\hline & & & National & Rural & Urban & North & Centre & South \\
\hline \multirow[t]{2}{*}{ Family } & Parents & $0-12$ & 9.6 & 9.1 & 10.9 & 8.1 & 10.1 & 11.2 \\
\hline & Marriage & $13-17$ & 6.3 & 7.6 & 4.1 & 7.3 & 6.8 & 4.4 \\
\hline \multirow[t]{3}{*}{ Nutrition } & Stunting & $0-4$ & 42.4 & 45.2 & 34.4 & 49.8 & 43.4 & 25.6 \\
\hline & Underweight & & 15.7 & 17.4 & 10.8 & 19.6 & 16.0 & 6.9 \\
\hline & Wasting & & 4.4 & 4.8 & 3.5 & 6.6 & 3.8 & 1.8 \\
\hline \multirow[t]{2}{*}{ Education } & Enrolment & $5-12$ & 25.9 & 29.9 & 15.4 & 37.9 & 24.5 & 7.6 \\
\hline & Primary & $13-17$ & 68.1 & 80.3 & 45.6 & 82.2 & 73.7 & 42.5 \\
\hline Labour & Labour & $5-17$ & 11.5 & 14.6 & 4.5 & 13.0 & 11.6 & 9.1 \\
\hline \multirow[t]{2}{*}{ Health } & Bed net & $0-4$ & 38.6 & 42.8 & 26.9 & 33.0 & 41.3 & 42.4 \\
\hline & Health facility & $0-17$ & 32.8 & 35.8 & 25.6 & 41.3 & 32.8 & 19.2 \\
\hline \multirow[t]{3}{*}{ WASH } & Water & $0-17$ & 42.5 & 54.4 & 13.3 & 50.7 & 48.5 & 15.9 \\
\hline & Water distance & & 9.0 & 11.8 & 2.1 & 12.8 & 7.6 & 5.7 \\
\hline & Sanitation & & 73.5 & 85.6 & 44.0 & 79.0 & 81.0 & 48.4 \\
\hline Participation & Information & $0-17$ & 24.9 & 30.2 & 12.0 & 35.2 & 26.5 & 4.7 \\
\hline \multirow[t]{3}{*}{ Housing } & Crowding & $0-17$ & 16.2 & 20.1 & 6.9 & 11.6 & 20.9 & 13.9 \\
\hline & Floor/roof & & 57.2 & 71.2 & 23.0 & 73.3 & 66.2 & 11.7 \\
\hline & Electricity & & 73.6 & 91.3 & 30.1 & 78.4 & 82.6 & 46.3 \\
\hline
\end{tabular}

Source: Authors' calculations based on 2014/15 Mozambican household budget survey data (IOF 2014/15)

Table 3 Deprivation rates by indicator and survey

\begin{tabular}{lllllll}
\hline & & $1996 / 97$ & $2002 / 03$ & $2008 / 09$ & $2014 / 15$ & Annual level change \\
\hline Family & Marriage & 8 & 8 & 7 & 6 & -0.09 \\
Nutrition & Stunting & 49 & & 45 & 42 & -0.38 \\
& Underweight & 25 & & 20 & 16 & -0.55 \\
& Wasting & 8 & & 7 & 4 & -0.22 \\
Education & Enrolment & 49 & 26 & 20 & 26 & -1.27 \\
& Primary & 95 & 90 & 77 & 68 & -1.49 \\
Health & Bed net & & & 54 & 39 & -2.58 \\
WASH & Water & & 63 & 58 & 42 & -1.75 \\
& Sanitation & & 87 & 83 & 74 & -1.10 \\
Participation & Information & 62 & 43 & 37 & 25 & -2.05 \\
Housing & Crowding & 12 & & 10 & 16 & 0.26 \\
& Floor/roof & 75 & & 67 & 57 & -0.96 \\
& Electricity & 94 & 92 & 86 & 74 & -1.13 \\
\hline
\end{tabular}

The definition of safe water differs slightly in 2002/03 and 2008/09 due to survey differences

Source: Authors' calculations based on 1996/97, 2002/03, 2008/09, and 2014/15 Mozambican household budget survey data (IAF 1996/97, IAF 2002/03, IOF 2008/09, and IOF 2014/15, respectively) 
Increased crowding is consistent with DHS evidence presented in Table 8. Using the $2008 \mathrm{MICS}$ and the 2011 DHS to measure primary net attendance ratios, UNICEF (2014) also finds evidence of reduced primary school enrolment between 2008 and 2011.

\subsection{Multidimensional Poverty}

In the AF approach, the multidimensional poverty index $\left(M_{0}\right)$ is the product of the incidence $(H)$ and intensity $(A)$ of poverty (Alkire et al. 2015). Incidence measures the proportion of the population that is multidimensionally poor those with a weighted deprivation count greater than the cut-off, which in this analysis is set to $k=1 / 3-$. Intensity measures the average weighted deprivation count among those who are multidimensionally poor. It is important to note that the level of the poverty index computed in this study is not directly comparable with consumption poverty rates or other indices based on the AF methodology. A specific index is rooted in the choice of indicators, deprivation thresholds, the poverty cut-off $(k)$, and weights, and is therefore strictly a reflection of deprivation given these parameters. So, weighted deprivation counts are driven by the age-group-specific weights and indicators outlined in Table 1. From these age-group parameters, the poverty index and incidence and intensity rates can be identified for all children.

Table 4 reports multidimensional poverty outcomes by area, age group, and sex. For reference, first-quarter and annual consumption poverty rates are also reported both for children and for all ages. Nationally, a poverty index level of 0.212 reflects that $46.3 \%$ of all children are deprived in at least one-third of the weighted indicators, and that these multidimensionally poor children are deprived in an average of $45.7 \%$ of the weighted indicators. Intensity of poverty is quite similar by area, age group, and sex and is only somewhat lower in the south $(41.1 \%) .{ }^{13}$ Therefore, differences in the poverty index across areas and age groups are driven primarily by the incidence rather than the intensity of poverty. Furthermore, relative patterns of multidimensional poverty as indicated by poverty incidence and the poverty index are nearly identical.

Nationally the multidimensional poverty incidence approximates the consumption poverty rate for children in the first quarter, 46.3 versus $49.0 \%$ respectively. However, the multidimensional divide between urban and rural areas and between northern and southern regions and provinces is greatly magnified and is reflected in both incidence and the poverty index (Fig. 1).

\footnotetext{
${ }^{13}$ The Southern part of Mozambique is unambiguously more developed than the rest of the country. This emerges in this analysis, but it has also been shown in a many other reports and articles (Arndt et al. (2016), DEEF (2016), Arndt et al. (2017) and Baez Ramirez et al. (2018), among others). Not only the number of poor people, from both the consumption and the multidimensional point of view, is lower, but they are also less poor - i.e. suffer from a lower number of deprivations - than the poor of the Centre and of the North. The lower levels of poverty in the South are associated with various factors; among the most important are: the presence of the capital Maputo in the region and the closeness of the southern provinces to the capital and to the more developed South Africa - not surprisingly, both incidence and intensity rates measured at provincial level are lower the closer we go to Maputo -. Moreover, better and denser infrastructures and public services are found in the southern region compared to the rest of the country (see for example INE (2015), DEEF (2016), Castigo and Salvucci (2017), Baez Ramirez et al. (2018)).
} 
Table 4 Multidimensional and consumption poverty by area, age group, and sex

\begin{tabular}{|c|c|c|c|c|c|c|c|}
\hline & \multicolumn{3}{|c|}{ Multidimensional poverty } & \multicolumn{4}{|c|}{ Consumption poverty } \\
\hline & & & & Children & All ages & & \\
\hline & Pov. index & Incidence & Intensity & 1st quarter & Annual & 1st quarter & Annual \\
\hline National & 0.212 & 46.3 & 45.7 & 49.0 & 51.1 & 43.9 & 46.1 \\
\hline Rural & 0.265 & 57.6 & 45.9 & 52.5 & 54.2 & 48.1 & 50.1 \\
\hline Urban & 0.082 & 18.6 & 44.4 & 40.5 & 43.4 & 34.8 & 37.4 \\
\hline North & 0.277 & 59.2 & 46.9 & 58.0 & 59.8 & 53.5 & 55.1 \\
\hline Centre & 0.232 & 51.2 & 45.4 & 48.5 & 50.2 & 43.9 & 46.2 \\
\hline South & 0.060 & 14.6 & 41.1 & 35.4 & 38.7 & 29.9 & 32.8 \\
\hline Niassa & 0.271 & 58.5 & 46.3 & 64.0 & 64.4 & 60.1 & 60.6 \\
\hline Cabo Delgado & 0.288 & 60.6 & 47.6 & 50.4 & 50.2 & 45.5 & 44.8 \\
\hline Nampula & 0.276 & 58.9 & 46.8 & 58.7 & 61.6 & 54.4 & 57.1 \\
\hline Zambezia & 0.271 & 59.1 & 45.8 & 60.0 & 61.5 & 54.2 & 56.5 \\
\hline Tete & 0.254 & 54.9 & 46.3 & 39.3 & 34.9 & 35.7 & 31.8 \\
\hline Manica & 0.172 & 39.1 & 44.0 & 38.8 & 44.2 & 35.2 & 41.0 \\
\hline Sofala & 0.178 & 40.8 & 43.5 & 42.4 & 48.7 & 38.1 & 44.2 \\
\hline Inhambane & 0.127 & 30.5 & 41.6 & 48.8 & 53.3 & 43.8 & 48.6 \\
\hline Gaza & 0.066 & 16.2 & 40.6 & 47.7 & 55.1 & 44.3 & 51.2 \\
\hline Maputo Province & 0.025 & 6.1 & 40.5 & 20.8 & 22.8 & 17.3 & 18.9 \\
\hline Maputo City & 0.005 & 1.3 & 38.5 & 17.8 & 15.2 & 13.7 & 11.6 \\
\hline Age $0-4$ & 0.206 & 44.9 & 45.8 & 50.5 & 52.4 & 50.5 & 52.4 \\
\hline Age 5-12 & 0.202 & 44.8 & 45.1 & 50.2 & 52.4 & 50.2 & 52.4 \\
\hline Age $13-17$ & 0.243 & 51.8 & 46.9 & 44.1 & 45.9 & 44.1 & 45.9 \\
\hline Age $18+$ & - & - & - & - & - & 37.7 & 40.1 \\
\hline Male & 0.216 & 47.3 & 45.6 & 49.7 & 51.8 & 43.9 & 46.0 \\
\hline Female & 0.208 & 45.4 & 45.8 & 48.4 & 50.4 & 43.9 & 45.8 \\
\hline
\end{tabular}

Source: Authors' calculations based on 2014/15 Mozambican household budget survey data (IOF 2014/15) and DEEF (2016)

Rural poverty incidence $(57.6 \%)$ is more than three times that of urban areas (18.6\%). Regional and provincial disparities are even greater, with the north four times poorer than the south, and the poorest provinces - Niassa, Cabo Delgado, Nampula, and Zambezia - are about 50 times as poor as Maputo City. While area differentials are also seen in consumption poverty rates, they are markedly lower relative to multidimensional poverty. As discussed, even if these results are not immediately comparable to similar analyses carried out on the same data, they certainly reinforce the findings contained in the Fourth National Poverty Assessment for Mozambique, which presented a strong regional divide with respect to multidimensional poverty, even using a different set of welfare indicators and weights (DEEF 2016). Figure 4 in the Appendix displays multidimensional poverty incidence by age group. Children aged 13-17 appear to be more deprived than younger children. However, age group 


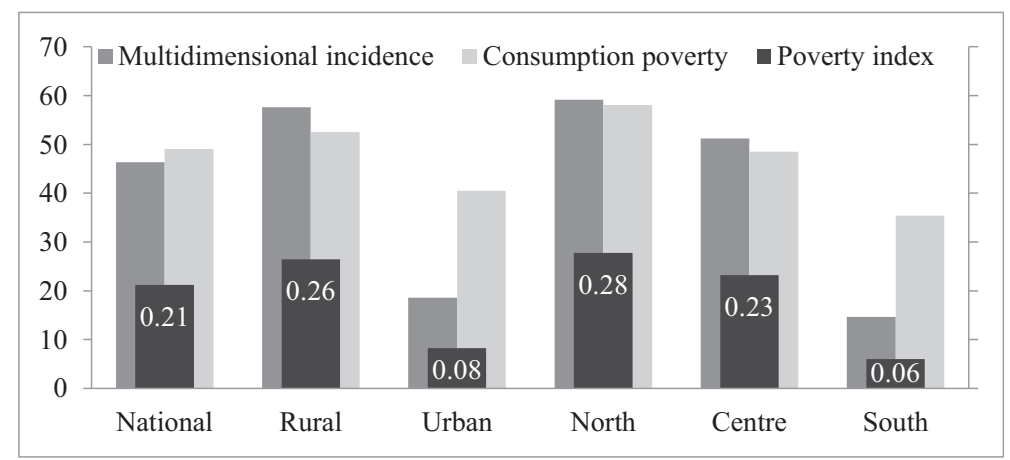

Fig. 1 Multidimensional and consumption poverty by area. Source: Authors' calculations based on 2014/15 Mozambican household budget survey data (IOF 2014/15) and DEEF (2016)

differentials are rooted in part in the choice of age-specific indicators and do not necessarily indicate that children aged 13-17 would be more deprived in a common set of indicators. This differential appears to be driven by the high rate of children who have not completed primary school, particularly in rural areas.

The sensitivity of our multidimensional poverty estimates to changes in the poverty cut-off are also analyzed. In Table 11 in the Appendix we show the poverty incidence in the case of the choice of different cut-offs $(k=0.2,0.3,0.4,0.5,0.6,0.7,0.8)$ at national and provincial level. Moreover, in order to understand the relative importance of each dimension for different age groups, it is important to study the relative contribution of specific welfare dimensions to the overall poverty index. Table 5 presents the relative degree to which each deprivation dimension contributes to the poverty index by age group. A few points emerge. First, for the nation and rural areas in the 0-4 and 5-12 age groups, housing, participation, WASH, health, and enrolment (5-12) are the dominant factors, with housing and WASH being the most significant of these. Health and participation $(0-4)$ contribute to urban poverty to a greater degree, while WASH

Table 5 Relative contributions of deprivation dimensions to the poverty index by age group (\%)

\begin{tabular}{llllllll}
\hline 0-4 age group & Parents & Nutrition & Health & WASH & Participation & Housing & \\
National & 2.56 & 11.12 & 18.33 & 21.53 & 20.82 & 25.64 & \\
Rural & 2.29 & 11.08 & 18.21 & 21.98 & 20.39 & 26.05 & Housing \\
Urban & 4.98 & 11.47 & 19.48 & 17.45 & 24.72 & 21.91 & Participation \\
5-12 age group & Parents & Enrolment & Labour & Health & WASH & 15.76 & 21.79 \\
National & 6.47 & 15.19 & 6.39 & 16.33 & 18.08 & 15.73 & 22.28 \\
Rural & 6.20 & 14.98 & 6.76 & 15.66 & 18.38 & 15.96 & 17.88 \\
Urban & 8.59 & 16.85 & 3.44 & 21.60 & 15.68 & Participation & Housing \\
13-17 age group & Marriage & Primary & Labour & Health & WASH & 11.78 & 19.21 \\
National & 3.23 & 28.84 & 6.27 & 14.57 & 16.10 & 11.68 & 19.89 \\
Rural & 3.10 & 28.71 & 6.49 & 13.66 & 16.48 & 12.45 & 14.60 \\
Urban & 4.16 & 29.77 & 4.76 & 20.73 & 13.54 & & \\
\hline
\end{tabular}

Source: Authors' calculations based on 2014/15 Mozambican household budget survey data (IOF 2014/15) 
and housing contribute to a slightly lesser degree, than in rural areas. Finally, the failure to complete primary school dominates the poverty index for the 13-17 age group more than any other dimension across age groups and areas.

As seen in Fig. 1, multidimensional and consumption poverty do not necessarily correspond. Multidimensional and consumption poverty rates in rural areas and northern and central regions are similar. In contrast, multidimensional poverty is considerably lower than consumption poverty in urban areas and the south. Multidimensional poverty rankings, obtained from the multidimensional poverty incidence estimates in Table 4, closely follow a north-to-south gradient, particularly when viewed in regional clusters. While consumption poverty rates also follow this overall pattern, there is a bit more shuffling among southern and central provinces. As a consequence, the resulting spearman rank correlation coefficient is pretty high, but sensibly lower than one (0.77). The standard correlation coefficient between provincial poverty rates rather than rankings is slightly higher at 0.81 .

Taking a deeper look at the relation between multidimensional and consumption poverty for urban and rural areas, Fig. 2 presents median adjusted daily household per capita consumption by weighted deprivation counts, which fall in the range $[0,1]$. Consumption is spatially adjusted based on regional poverty line estimates (DNPO 1998, 2004; MPD and DNEAP 2010; DEEF 2016). Overall, the figure shows that median household consumption decreases as the deprivation count increases. The relationship between multidimensional and consumption poverty is markedly different in rural and urban areas. Children just below the multidimensional poverty level $(k=1$ / 3 ) live in households with median consumption below the spatially adjusted poverty line $(z=29.2)$. While this holds in both urban and rural areas, urban children with deprivation levels greater than 0.20 have median consumption levels below the poverty line and are poorer than rural children. This gap widens at greater deprivation levels. The figure indicates that rural children experiencing severe multidimensional poverty have only moderately low median consumption levels. Furthermore, the relationship

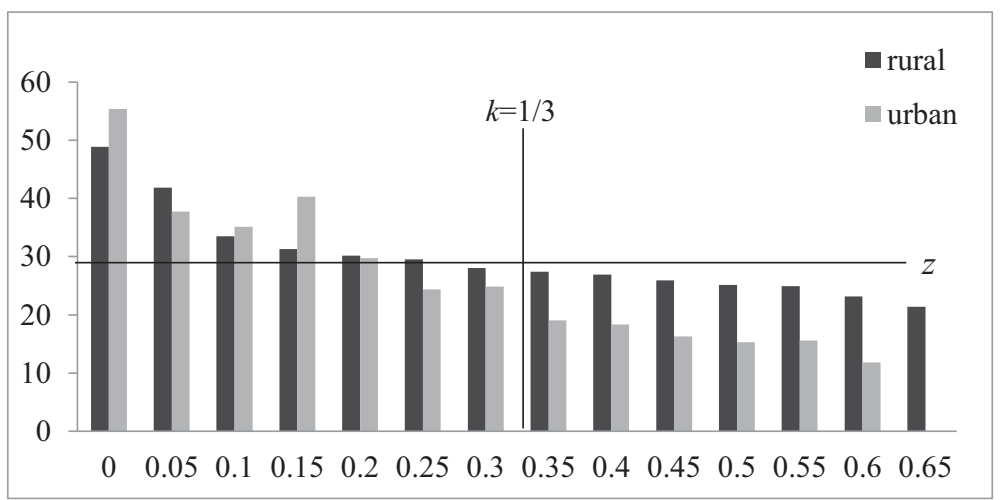

Fig. 2 Median daily per capita consumption by weighted deprivation counts Notes: Median consumption is reported by weighted deprivation counts rounded to the nearest five-hundredth. The graph is truncated to include deprivation counts below 0.6 and 0.65 in urban and rural areas respectively due to the small number of observations for higher deprivation counts (see Table 11 in the Appendix). The spatially adjusted poverty line, $z$, equals 29.2 Mozambican meticais (MT). This number is not comparable to unadjusted regional and national average poverty lines reported in the fourth national poverty assessment (DEEF 2016). Source: Authors' calculations based on 2014/15 Mozambican household budget survey data (IOF 2014/15) and DEEF (2016) 


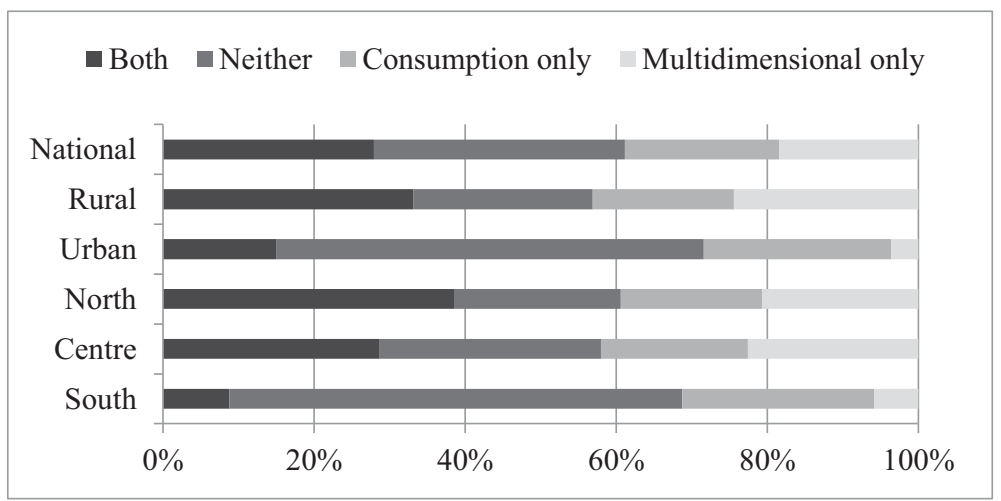

Fig. 3 Overlap between multidimensional and consumption poverty. Source: Authors' calculations based on 2014/15 Mozambican household budget survey data (IOF 2014/15) and DEEF (2016)

between consumption and multidimensional poverty is flatter for rural children, which might suggest that urban multidimensional poverty may be relatively more responsive to improvements in household consumption. This is not surprising given that a large share of rural households is primarily engaged in subsistence farming rather than income-generating activities.

Given the different nature of consumption and multidimensional poverty, and the different way it presents itself in different locations and contexts, it is important to also study the overlapping patterns between the two poverty measures. In Fig. 3 we consider the overlap between multidimensional and consumption poverty by displaying the percentage of children with different combinations of poverty outcomes. The relationship between multidimensional and consumption poverty status is strongest in urban areas, where $72 \%$ of children are poor either by both or by neither definition, compared with $57 \%$ in rural areas. Rural and northern children are most likely to be poor by both definitions while urban and southern children are most likely to not be poor by either definition. If a child is deprived in only one form of poverty it is more often multidimensional poverty in rural areas and the north but consumption poverty in urban areas and the south. Urban and southern children are unlikely to be only multidimensionally poor (4 and $6 \%$, respectively).

The relationship between child consumption and multidimensional poverty presented in Figs. 2 and 3 is extremely important and deserves further attention and analysis. A deeper analysis of its determinants might suggest that focusing on reducing consumption poverty in urban areas may be effective in alleviating both forms of poverty in those areas, whereas efforts to simultaneously improve both consumption levels and multidimensional deprivation levels may be key to improving child wellbeing in rural settings. ${ }^{14}$

\footnotetext{
${ }^{14}$ An effort to analyse the determinants of each type of poverty using the same set of data for Mozambique has been carried out in Ibraimo and Salvucci (2017).
} 


\section{International multidimensional poverty comparisons}

To provide international and temporal context to the situation of Mozambican children, we also conduct AF analysis based on DHS surveys in two time periods for Mozambique and four additional countries in the region - Malawi, Tanzania, Zambia, and Zimbabwe -. International deprivation indicators are drawn from DHS data which address household and child welfare in a harmonized manner across countries and, as much as possible, over time. The use of such harmonized data allows consistent and universally applicable deprivation indicators to be defined across time and space, which results in an internationally relevant and comparable measure of basic wellbeing. ${ }^{15}$ This stands in contrast to monetary poverty analysis that is rooted in either national or global poverty lines such as the World Bank US\$1.90 or $\$ 2.20$ a day lines. While national poverty lines identify the local costs of meeting basic needs but are not internationally comparable, the reverse is true with global poverty lines. A second set of indicators was defined with as little modification as possible to those in Table 1 to provide consistent international comparisons. These indicators are presented in Table 6. Major differences from the IOF indicators include the absence of child labour and distance to health facilities indicators, an alternative sanitation threshold, and the use of floor only to measure housing quality. The DHS inquires about the marital status of children aged 15 and older. Consequently, the family dimension is measured by the parent indicator for children aged 0-14 and the marriage indicator for children aged 15-17.

Table 7 provides specific sample details, including years covered, sample sizes, and the percentage of the sample that is rural, as well as the percentage of children falling into each age group. ${ }^{16}$ For each country, data are used from the most recent DHS survey and a DHS survey from the early 2000s. ${ }^{17}$

\subsection{Deprivation rates}

Table 8 displays deprivation rates in the first and second period for each country. In the final survey period, Mozambique has the highest deprivation rates in more than half of

\footnotetext{
${ }^{15}$ A broader attempt to estimate multidimensional poverty in Sub-Saharan Africa has been recently implemented by de Milliano and Plavgo (2018) using DHS and MICS data and a different set of welfare indicators, but applying the Multiple Overlapping Deprivation Analysis (MODA) methodology.

${ }^{16}$ Data used in this analysis are restricted to children with non-missing values for all age-group-specific indicators, and therefore sample sizes reported in Table 7 are smaller than the full DHS child samples. Anthropometric, marriage, and, to a much lesser degree, distance-to-water data have the greatest impacts on sample sizes. The 2015 Malawi DHS collected anthropometric data for a subsample of children that, after dropping missing values among eligible children, amounted to about $30 \%$ of the full under-5 sample, or 5500 children. Furthermore, though all children under 5 were eligible to be measured in the remaining country surveys, a sizeable number of children were either not measured or flagged and dropped for potentially infeasible measurements. Thus, the remaining under- 5 samples used in this study range from about 80 to $90 \%$ of the full sample. In several first-period studies (Malawi, Mozambique, and Tanzania), only the subsample of boys selected for the men's questionnaires were queried on their marital status. Thus, these samples are imbalanced, with nearly all girls in the 13-17 age group retained compared with 53 to $60 \%$ of boys. However, since few boys are married, sensitivity analysis was conducted comparing multidimensional poverty using two approaches to this issue: (1) dropping all boys without marital status data and (2) assuming all boys without this data are unmarried. Differences in poverty outcomes were negligible and therefore we opt to drop boys without data.

${ }^{17}$ The 2001 Zambia DHS was not used due to the absence of data on number of rooms in the household.
} 
Table 6 International DHS deprivation indicators

\begin{tabular}{|c|c|c|c|c|c|}
\hline \multirow[t]{2}{*}{ Dimension } & \multirow[t]{2}{*}{ Indicator } & \multirow[t]{2}{*}{ Threshold } & \multicolumn{3}{|c|}{ Weight by age group } \\
\hline & & & $0-4$ & $5-12$ & $13-17$ \\
\hline \multirow[t]{2}{*}{ Family } & Parents & $\begin{array}{l}\text { At least one parent dead or } \\
\text { it is not known }(0-14)\end{array}$ & $(1 / 6)$ & $(1 / 5)$ & \\
\hline & Marriage & $\begin{array}{l}\text { Child ever married or in an } \\
\text { informal union }(15-17)\end{array}$ & & & $(1 / 5)$ \\
\hline \multirow[t]{3}{*}{ Nutrition } & Stunting & $\begin{array}{l}\text { Height for age less than }-2 \\
\text { standard deviation from } \\
\text { WHO reference }\end{array}$ & $(1 / 18)$ & & \\
\hline & Underweight & $\begin{array}{l}\text { Weight for age less than }-2 \\
\text { standard deviation from } \\
\text { WHO reference }\end{array}$ & $(1 / 18)$ & & \\
\hline & Wasting & $\begin{array}{l}\text { Weight for height for age less } \\
\text { than }-2 \text { standard deviation } \\
\text { from WHO reference }\end{array}$ & $(1 / 18)$ & & \\
\hline \multirow[t]{2}{*}{ Education } & Enrolment & $\begin{array}{l}\text { Did not attend school in the } \\
\text { current school year }\end{array}$ & & $(1 / 5)$ & \\
\hline & Primary & $\begin{array}{l}\text { Did not complete seven years } \\
\text { of schooling }\end{array}$ & & & $(1 / 5)$ \\
\hline Health & Bed net & Did not sleep under a bed net & $(1 / 6)$ & & \\
\hline \multirow[t]{3}{*}{ WASH } & Water & Unimproved source of drinking water & $(1 / 18)$ & $(1 / 15)$ & $(1 / 15)$ \\
\hline & Distance to water & Water source more than 30 min away & $(1 / 18)$ & $(1 / 15)$ & $(1 / 15)$ \\
\hline & Sanitation & No sanitation facility & $(1 / 18)$ & $(1 / 15)$ & $(1 / 15)$ \\
\hline Participation & Information & $\begin{array}{l}\text { No information device (TV, radio, or } \\
\text { any phone) }\end{array}$ & $(1 / 6)$ & $(1 / 5)$ & $(1 / 5)$ \\
\hline \multirow[t]{3}{*}{ Housing } & Crowding & More than four people per room & $(1 / 18)$ & $(1 / 15)$ & $(1 / 15)$ \\
\hline & Floor and roof & Floor of primitive materials & $(1 / 18)$ & $(1 / 15)$ & $(1 / 15)$ \\
\hline & Electricity & No electricity in the household & $(1 / 18)$ & $(1 / 15)$ & $(1 / 15)$ \\
\hline
\end{tabular}

Source: Authors' elaboration

the indicators (marriage, stunting, underweight, wasting, enrolment, primary, water, and sanitation) and is within a few points of the highest rate in several other indicators (parents, water distance, information, and floor). Performance in the enrolment, primary, water, and sanitation indicators is particularly poor; however, these are the areas where Mozambique has also made impressive gains.

Table 7 Sample information for DHS comparisons

\begin{tabular}{|c|c|c|c|c|c|c|c|c|c|c|c|}
\hline & & \multicolumn{2}{|c|}{ Sample size } & \multicolumn{2}{|c|}{ Per cent rural } & \multicolumn{6}{|c|}{ Per cent by age group } \\
\hline & & & & & & \multicolumn{2}{|l|}{$0-4$} & \multicolumn{2}{|c|}{$5-12$} & \multicolumn{2}{|c|}{$13-17$} \\
\hline & Survey years & $t_{1}$ & $t_{2}$ & $t_{1}$ & $t_{2}$ & $t_{1}$ & $t_{2}$ & $t_{1}$ & $t_{2}$ & $t_{1}$ & $t_{2}$ \\
\hline Malawi & 2004,2015 & 28,668 & 52,050 & 0.86 & 0.87 & 0.30 & 0.11 & 0.53 & 0.62 & 0.17 & 0.27 \\
\hline Mozambique & 2003,2011 & 28,950 & 32,028 & 0.68 & 0.70 & 0.31 & 0.31 & 0.53 & 0.48 & 0.16 & 0.20 \\
\hline Tanzania & 2004,2015 & 23,829 & 33,001 & 0.79 & 0.74 & 0.34 & 0.31 & 0.47 & 0.47 & 0.18 & 0.22 \\
\hline Zambia & 2007,2013 & 18,248 & 42,609 & 0.67 & 0.64 & 0.30 & 0.28 & 0.47 & 0.49 & 0.22 & 0.23 \\
\hline Zimbabwe & 2005,2015 & 20,162 & 20,490 & 0.75 & 0.75 & 0.24 & 0.29 & 0.49 & 0.46 & 0.26 & 0.25 \\
\hline
\end{tabular}

Source: Authors' calculations based on the 2004 and 2015 DHS for Malawi; the 2003 and 2011 DHS for Mozambique; the 2004 and 2015 DHS for Tanzania; the 2007 and 2013 DHS for Zambia; and the 2005 and 2015 DHS for Zimbabwe (DHS 2017) 
Table 8 Deprivation rates (per cent) and annual level changes

\begin{tabular}{|c|c|c|c|c|c|c|c|c|c|c|c|c|c|c|c|}
\hline & \multicolumn{3}{|c|}{ Malawi } & \multicolumn{3}{|c|}{ Mozambique } & \multicolumn{3}{|c|}{ Tanzania } & \multicolumn{3}{|c|}{ Zambia } & \multicolumn{3}{|c|}{ Zimbabwe } \\
\hline & $t_{1}$ & $t_{2}$ & change & $t_{1}$ & $t_{2}$ & change & $t_{1}$ & $t_{2}$ & change & $t_{1}$ & $t_{2}$ & change & $t_{1}$ & $t_{2}$ & change \\
\hline Parents & 14 & 12 & -0.21 & 11 & 12 & 0.11 & 9 & 8 & -0.14 & 14 & 10 & -0.54 & 24 & 15 & -0.88 \\
\hline Marriage & 14 & 6 & -0.69 & 20 & 16 & -0.56 & 11 & 7 & -0.41 & 5 & 4 & -0.14 & 7 & 8 & 0.04 \\
\hline Stunting & 52 & 38 & -1.35 & 47 & 43 & -0.54 & 44 & 34 & -0.91 & 46 & 40 & -0.92 & 34 & 27 & -0.78 \\
\hline Underweight & 17 & 12 & -0.52 & 20 & 15 & -0.59 & 16 & 13 & -0.27 & 15 & 15 & 0.02 & 13 & 8 & -0.50 \\
\hline Wasting & 6 & 3 & -0.30 & 5 & 6 & 0.09 & 3 & 4 & 0.09 & 5 & 6 & 0.15 & 7 & 3 & -0.37 \\
\hline Enrolled & 16 & 5 & -1.04 & 36 & 25 & -1.31 & 27 & 20 & -0.63 & 24 & 23 & -0.31 & 9 & 3 & -0.54 \\
\hline Primary & 77 & 68 & -0.75 & 92 & 71 & -2.60 & 77 & 46 & -2.81 & 62 & 55 & -1.15 & 27 & 28 & 0.16 \\
\hline Bed net & 79 & 50 & -2.65 & 90 & 61 & -3.58 & 69 & 40 & -2.67 & 67 & 57 & -1.60 & 93 & 89 & -0.47 \\
\hline Water & 39 & 14 & -2.28 & 62 & 48 & -1.68 & 55 & 45 & -0.86 & 60 & 39 & -3.47 & 27 & 28 & 0.09 \\
\hline Water distance & 7 & 11 & 0.32 & 6 & 10 & 0.49 & 12 & 12 & -0.08 & 2 & 3 & 0.11 & 5 & 6 & 0.09 \\
\hline Sanitation & 15 & 5 & -0.85 & 49 & 40 & -1.02 & 15 & 12 & -0.29 & 25 & 17 & -1.27 & 36 & 27 & -0.90 \\
\hline Information & 35 & 35 & 0.03 & 39 & 33 & -0.73 & 38 & 14 & -2.18 & 33 & 20 & -2.10 & 51 & 9 & -4.23 \\
\hline Crowding & 21 & 15 & -0.61 & 14 & 17 & 0.31 & 15 & 12 & -0.30 & 32 & 23 & -1.54 & 16 & 13 & -0.34 \\
\hline Floor & 80 & 76 & -0.35 & 75 & 74 & -0.18 & 77 & 63 & -1.27 & 63 & 59 & -0.73 & 38 & 31 & -0.72 \\
\hline Electricity & 93 & 91 & -0.25 & 90 & 79 & -1.42 & 91 & 83 & -0.72 & 81 & 76 & -0.76 & 73 & 75 & 0.26 \\
\hline
\end{tabular}

Source: Authors' calculations based on the 2004 and 2015 DHS for Malawi; the 2003 and 2011 DHS for Mozambique; the 2004 and 2015 DHS for Tanzania; the 2007 and 2013 DHS for Zambia; and the 2005 and 2015 DHS for Zimbabwe (DHS 2017)

The relatively early final survey used for Mozambique (2011 compared with 2013 or 2015) may overstate deprivation relative to the other study countries that have later final surveys. For example, Mozambique made enormous strides in reducing the percentage of under-5 s who do not sleep under a bed net from $90 \%$ in 2003 to $61 \%$ in 2011 . The $2014 / 15$ IOF rate of $39 \%$ provides evidence that bed net deprivation may have further declined in recent years. The explosion of mobile phone usage in recent years may also mean that Mozambique's information deprivation is overstated - the 2011 DHS deprivation rate is $33 \%$ compared with $25 \%$ in the $2014 / 15$ IOF. This hypothesis is corroborated by the findings contained in the 2015 DHS Mozambique AIDS Indicators Survey (DHS/AIS) and the 2018 DHS Mozambique Malaria Indicators Survey (DHS/MIS) final reports. Even though not as wide-ranging as standard DHS surveys, these two surveys provide useful indications on more recent trends for some of the welfare indicators considered in the present analysis. Concerning bed net use for example, the 2015 DHS/AIS final report shows that about $48 \%$ of children under five slept under an insecticide-treated net the night before the survey (MISAU et al. 2016), and the 2018 DHS/MIS final report informs that $73 \%$ of children under 5 slept under an insecticide-treated net the night before the survey (INS and ICF 2019), which would put Mozambique's figures in line with those of the other countries analysed. ${ }^{18}$ Moreover, using these data sets to compute the deprivation in information

\footnotetext{
${ }_{18}$ Nonnegligible improvements are also registered in the areas of access to safe water and distance to water sources, sanitation, access to electricity and floor quality (INS and ICF 2019).
} 
Table 9 Multidimensional poverty outcomes by country and survey period

\begin{tabular}{|c|c|c|c|c|c|c|c|c|c|c|}
\hline & \multicolumn{2}{|l|}{$H$} & \multicolumn{2}{|l|}{$A$} & \multicolumn{2}{|l|}{$M_{0}$} & \multicolumn{2}{|c|}{ Annual change $\left(M_{0}\right)$} & \multicolumn{2}{|c|}{$\%$ of $\mathrm{MZ}\left(M_{0}\right)$} \\
\hline & $t_{1}$ & $t_{2}$ & $t_{1}$ & $t_{2}$ & $t_{1}$ & $t_{2}$ & Level & $\%$ & $t_{1}$ & $t_{2}$ \\
\hline Malawi & 60.6 & 48.1 & 47.3 & 44.0 & 0.287 & 0.212 & -0.007 & -2.4 & 80 & 73 \\
\hline Mozambique & 69.4 & 57.6 & 51.3 & 50.2 & 0.356 & 0.289 & -0.008 & -2.3 & - & - \\
\hline Tanzania & 62.7 & 37.6 & 48.6 & 44.3 & 0.305 & 0.166 & -0.013 & -4.1 & 86 & 58 \\
\hline Zambia & 56.7 & 42.8 & 49.8 & 46.3 & 0.283 & 0.198 & -0.014 & -5.0 & 79 & 69 \\
\hline Zimbabwe & 55.6 & 29.5 & 49.6 & 43.2 & 0.276 & 0.127 & -0.015 & -5.4 & 78 & 44 \\
\hline
\end{tabular}

Source: Authors' calculations based on the 2004 and 2015 DHS for Malawi; the 2003 and 2011 DHS for Mozambique; the 2004 and 2015 DHS for Tanzania; the 2007 and 2013 DHS for Zambia; and the 2005 and 2015 DHS for Zimbabwe (DHS 2017)

for Mozambique in 2015 and 2018, we obtain the result that this is equal to $25.7 \%$ in 2015 and to $26.3 \%$ in 2018, much lower rates compared to 2011. These partial results confirm that indeed Mozambique's deprivation could probably be overstated in the international comparison presented. ${ }^{19}$ Access to mobile phones, in particular, has been found to bring about positive changes in other areas as well; Sekabira and Qaim (2017) for example find that in Uganda mobile phone use seems to be associated with increased household income, and with better gender equality and food security. ${ }^{20}$ Table 12 in the Appendix provides final-period deprivation rates by sex for nonhousehold indicators.

\subsection{Multidimensional poverty}

Mozambique's multidimensional poverty, in terms of all three measures (incidence, intensity, and poverty index), exceeds that of its neighbours by a large margin (Table 9). Mozambique makes relatively small annual-level and percentage gains in poverty incidence. Moreover, poor children in Mozambique face the highest average percentage of deprivations. Initially this difference is small (1-4 percentage points), but Mozambique reduced intensity by considerably less than its neighbours ( 1 percentage point compared to 3-6 percentage points). Thus, the resulting poverty index reflects this divergence in both the incidence and the intensity of poverty.

The final two columns of Table 9 report each country's poverty index as a percentage of Mozambique's index. Most striking is the considerable increase in the disparity between Mozambique and Tanzania, which had the second-highest deprivation rate in

\footnotetext{
19 The two databases presented in this paragraph, the 2015 DHS Mozambique AIDS Indicators Survey (DHS/ AIS) and the 2018 DHS Mozambique Malaria Indicators Survey (DHS/MIS), were not available when the analysis contained in this study was carried out. They both became available after the submission of the study for publication.

Mozambique's deprivation is probably overstated also in the international comparison analyses contained in the Global Multidimensional Poverty Index published in the last few years (for example, Alkire and Robles 2016).

${ }^{20}$ See also Khan et al. (2018) for the impact of mobile phones on nutrition service delivery in rural Bangladesh.
} 
the first period. Tanzania reduced its poverty index by $4.1 \%$ annually, compared with Mozambique's $2.4 \%$ reduction.

While relative improvements in rural areas are similar to national trends, progress in urban areas follows a distinct pattern. Notably, Mozambique, Malawi, and Tanzania reduced the urban poverty index by about 0.075 . When translated to annual gains, Mozambique achieved the greatest reduction in the poverty index, and, though not reported here, in poverty incidence as well. Zambia and Zimbabwe started at a substantially lower urban deprivation level and achieved smaller gains. As a result, in the second period, urban Malawi and Tanzania experienced lower multidimensional poverty than urban Zambia (the rural and urban poverty index in both periods are reported in Fig. 5 in the Appendix).

\section{Discussion and limitations of the research}

Poverty is increasingly considered and studied as a multidimensional phenomenon (UNDP and OPHI 2019). In this context, following the release of the 2014/15 IOF data Mozambique has developed in 2016 a national multidimensional poverty index based on a wide range of welfare indicators and dimensions (DEEF 2016). This has inspired the construction of a multidimensional poverty index specific to children belonging to different age groups. During 2016, UNICEF-Mozambique organized a workshop to discuss about what constitutes a deprivation for children in the Mozambican context and it emerged that the set of welfare indicators used to measure poverty for the entire population was not completely satisfactory to fully describe child poverty. A new set of welfare indicators and dimensions was then developed and it inspired the construction of a multidimensional child poverty index, which constitutes the core contribution of the present study. ${ }^{21}$ The multidimensional child poverty index presented is based on a rich and relatively recent household budget survey data (IOF 2014/15) that allowed the inclusion of specific child-related characteristics not explored in the national multidimensional poverty index, such as the Parents and the Marriage indicators, a more complete assessment of nutrition status, the Bed Net and Child Labour characteristics. Moreover, we also differentiated the set of welfare indicators according to the age of the child.

Even though the multidimensional child poverty results replicate some of the key findings obtained using the national multidimensional poverty, some of the childrelated characteristics show different temporal trends or shed light on age-group specific deprivations. In particular, most indicators show improvements over time, following the rapid growth experienced by Mozambique during the last 25 years, but some welfare indicators particularly relevant to children aged $0-17$, such as child marriage, wasting and stunting, stagnated or only modestly improved. Regarding nutrition indicators, this reflects a trend observed also at global and regional level. In particular, it has emerged that "stunting has declined twice as quickly in Asia and Latin America and the Caribbean as it has in Africa" (UNICEF/WHO/World Bank 2017). Also, stunting has been found to be highly correlated with access to safe water and to

\footnotetext{
${ }^{21}$ As discussed, the set of welfare indicators and dimensions selected during the 2016 workshop organized by UNICEF-Mozambique also constitutes the basis for the analyses contained in Ferrone et al. (2019).
} 
quality sanitation, two indicators that have improved over time, but not so much in rural areas and in the in the Northern regions, where most stunted children live (DEEF 2016; Castigo and Salvucci 2017). Also, UN-Mozambique (2016) states that the immediate causes of chronic undernutrition in Mozambique are inadequate quantity and quality of the diet and high rates of infectious diseases, which have improved, but, again, not as much as other indicators (DEEF 2016). UN-Mozambique (2016) also confirms that the major underlying causes of chronic undernutrition are income poverty and food insecurity; these dimensions are slowly but constantly improving, which may bring about more tangible improvements in child nutrition over the next few years.

With respect to child marriage, this appears to be linked to cultural factors as well as to other welfare indicators, and is thus more difficult to observe rapid changes in this variable with respect to other indicators. For this characteristic as well, the slow decrease observed seems to be part of a global phenomenon. ${ }^{22}$ Nonetheless, improving access to education, health services and job opportunities for both genders is key to observe a change in this indicator as well. The progress observed in Mozambique in these access indicators over recent years is thus promising, and is expected that in the next few years child marriage rates could also go down, as it happened in other countries that experienced similar development trajectories in the recent past (UNICEF and UNFPA 2018).

Using the Alkire-Foster methodology, we aggregated the various welfare indicators and dimension into a comprehensive multidimensional poverty index (Alkire and Foster 2007; Alkire et al. 2015, 2017). We estimate that about $46 \%$ of all children aged 0 to 17 in Mozambique can be considered multidimensionally poor. This is equivalent to more than 6 million children and, though not immediately comparable, it seems a substantially higher percentage than the multidimensional poverty incidence found at global level, where about $37 \%$ of all kids are found to be multidimensionally poor (Alkire et al. 2017). Given the widespread poverty that exists in Mozambique (DEEF 2016; Baez Ramirez et al. 2018) this is not a complete surprise, but it raises concern on the situation of children and future developments of the country; also in light of the fact that Mozambique continues to have multidimensional poverty levels that exceed those of its neighbours - Malawi, Tanzania, Zambia, and Zimbabwe - by a large margin. Notwithstanding the improvements observed, performance in the enrolment, primary, water, and sanitation indicators seems to be particularly poor, which also influences nutrition and other indicators. This greatly depends on the very low starting levels for Mozambique, which only got out of a devastating civil war in 1992. However, it is difficult to explain the different pace at which Tanzania managed to reduce its poverty index compared to Mozambique (4.1 versus 2.4\%). One explanation comes from the fact that Mozambique's development in recent years has been highly unequal. Rural areas and most central-northern regions have experienced much lower gains in terms of welfare than urban areas and southern provinces. This has been documented in the present study for what concerns child-related characteristics, but it seems to be valid for the whole population: Arndt et al. (2016), DEEF (2016), Arndt

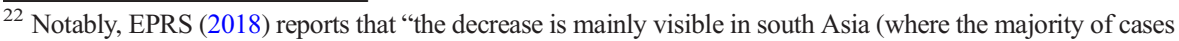
still occur); in sub-Saharan Africa, the rate of child marriages is slowly decreasing, but not enough to offset the fast demographic growth, which means that the absolute number of child marriages in the region will continue to increase $[\ldots][$ and] a change in mind-set can only be driven by long- term, multi-pronged programmes" (EPRS 2018).
} 
et al. (2017) and Baez Ramirez et al. (2018), among others, document in detail this unequal development process and discuss possible determinants. Prominently, DEEF (2016) acknowledges that if only relatively small improvements continue to take place in the rural areas of the Centre-North - that is, where most people reside -, then it is highly unlikely that big improvements could be registered at national level. We highlighted here that Mozambique achieved the greatest reduction in the urban poverty index among the countries considered, which confirms the non-inclusiveness of its development process. At regional level, the four poorest provinces - Niassa, Cabo Delgado, Nampula, and Zambezia, all located in the Centre-North - are about 50 times poorer than the richest - Maputo City -. Moreover, a much higher percentage of children in rural areas and northern provinces are simultaneously poor from the consumption and the multidimensional points of view (about 33 and 38\%, compared with 9 and $15 \%$ in urban areas and the south), which makes them even more vulnerable. $^{23}$ This geographically unequal outcomes have certainly to do with the shape and colonial history of the country, but developments in recent years seem to have found it difficult to revert historical development patterns (see also the World Bank Mozambique Economic Update for a recent discussion on the need to address the growing inequality and on Mozambique's economic progress becoming increasingly less inclusive (Mahdi et al. 2018)).

Certainly, the analysis presented suffers from a series of limitations that have to do both with the data and the methodology. In particular, as discussed in Section 3.1, some of the dimensions that were felt as important to influence child deprivation, such as Security, Participation and Leisure, could not be adequately measured using the 2014/15 IOF data, and were therefore excluded from this assessment. ${ }^{24}$ Moreover, not all the welfare indicators and dimensions selected could be consistently and precisely defined using previous household budget survey data and the same underlying assumptions, which made it problematic to calculate child-specific deprivation rates and trends over time. Therefore, the estimates presented in Table 3 tried to limit as much as possible the modifications to the general indicator definitions, but did not allow to compute a consistent multidimensional poverty index over time based on the indicators presented in Table 1. The same effort to reduce the discrepancies between welfare indicator and dimension definitions across countries was done in Section 4, but - as discussed -, it has not been possible to obtain the exact same set of indicators and dimensions for all countries.

From the methodological point of view, this study suffers from the same limitations that affect most of the analyses implemented using the Alkire-Foster methodology, that is, a somewhat arbitrary selection of the welfare indicators and dimensions, of the way to group indicators into dimensions, of the weights assigned to each dimension/ indicator and of the poverty cutoff, which determines the amount of deprivations sufficient for a person to be considered poor (Alkire and Foster 2011). Even though this freedom of choice is often perceived as a disadvantage - since it is possible to come

\footnotetext{
${ }^{23}$ While further analysis is merited, the results presented in this study suggest that reducing consumption poverty in urban areas may also be effective in alleviating urban multidimensional poverty. However, rural multidimensional poverty appears to be less responsive to consumption, and therefore efforts to simultaneously improve both consumption and multidimensional deprivation levels may be essential to improve child wellbeing in rural settings.

${ }^{24}$ The Mozambican National Statics Institute is considering the inclusion of some of the indicators linked to these missing dimensions in future household budget surveys.
} 
up with different specifications and obtain very different results -, nonetheless it allows to adapt the general multidimensional poverty framework to specific country situations - while at the same time limiting the possibility to compare results across countries using different specifications.$-{ }^{25}$ Notwithstanding the existing limitations, we believe to have managed to compute a broad aggregated multidimensional poverty index that: i) made use of the most of the information available in the data; ii) is in line with the literature on multidimensional child poverty estimation; iii) tried to retain some of the most important characteristics of the general multidimensional poverty framework used for the assessment of deprivation in other countries.

\section{Conclusions}

During the last 25 years, Mozambique has experienced periods of rapid and steady growth, accompanied by significant reduction in both multidimensional and consumption poverty, especially between 1996/97 and 2002/03 and between $2008 / 09$ and 2014/15. However, it appears that not all provinces or areas and not all population groups have benefited in the same way. In this study, we focused on multidimensional child wellbeing, computed using the data from the most recent household budget survey implemented in 2014/15. It emerged that some welfare indicators particularly relevant to children aged $0-17$, such as child marriage and stunting, appear to have been more resistant to advancement than other indicators.

Using the Alkire-Foster methodology, we compute that $46.3 \%$ of all children can be considered multidimensionally poor and that these multidimensionally poor children are deprived in an average of $45.7 \%$ of the weighted indicators. Moreover, most welfare indicators appear to be substantially worse for rural than urban areas and to worsen moving from the south to the north. This translates into a substantial multidimensional poverty divide between urban and rural areas and between northern and southern provinces. A significant, and striking, result of our analysis is that rural poverty incidence for children aged 0-17 is more than three times that of urban areas, and the four poorest provinces are about 50 times poorer than the richest. Considering multidimensional and consumption poverty, we also notice that a much higher percentage of children in rural areas and northern provinces are simultaneously poor from the consumption and the multidimensional points of view.

The wellbeing situation and trends of Mozambican children were also compared to those of Malawi, Tanzania, Zambia, and Zimbabwe using two compatible recent waves of DHS data for the five countries. Our findings suggest that despite impressive gains in some welfare indicators, Mozambique continues to have the highest child welfare deprivation rates in more than half of the selected indicators, and that its multidimensional poverty level exceeds that of its neighbours by a large margin. At the same time, it is worth highlighting that

\footnotetext{
${ }^{25}$ The Global MPI is a particular application of the Alkire-Foster methodology that was developed to allow cross-country comparisons using standardized indicator, dimension and cutoff definitions.
} 
Mozambique achieved the greatest reduction in the urban poverty index, which once more confirms the impression of an uneven development process, not inclusive of all regions or population groups, particularly children in rural and central/northern regions.

These results inevitably lead to the conclusion that a series of targeted policies that explicitly consider the specificities of child welfare should be put in place to ensure that growth and poverty reduction experienced at the national level for the population as a whole are also translated into better living conditions for children. Increased efforts to tackle chronic malnutrition, improve access to safe water sources and quality sanitation, and reduce dropout rates among teenagers seem particularly urgent from this point of view, and government expenditures in these sectors should be protected even during economic slowdowns like the one currently experienced by Mozambique.

Acknowledgements The authors would like to thank the participants in the 2018 Nordic Conference on Development Economics, Aalto University School of Business, Helsinki, Finland, 11-12 June 2018, for the useful comments and questions provided.

This study has been prepared within the UNU-WIDER project on 'Inclusive growth in Mozambique - scaling-up research and capacity' implemented in collaboration between UNU-WIDER, University of Copenhagen, University Eduardo Mondlane, and the Mozambican Ministry of Economics and Finance. The project is financed through specific programme contributions by the governments of Denmark, Finland, Norway, and Switzerland. This study has also benefitted from financial support by UNICEF-Mozambique.

Open Access This article is licensed under a Creative Commons Attribution 4.0 International License, which permits use, sharing, adaptation, distribution and reproduction in any medium or format, as long as you give appropriate credit to the original author(s) and the source, provide a link to the Creative Commons licence, and indicate if changes were made. The images or other third party material in this article are included in the article's Creative Commons licence, unless indicated otherwise in a credit line to the material. If material is not included in the article's Creative Commons licence and your intended use is not permitted by statutory regulation or exceeds the permitted use, you will need to obtain permission directly from the copyright holder. To view a copy of this licence, visit http://creativecommons.org/licenses/by/4.0/.

\section{Appendix}

Table 10 Deprivation rates by indicator, area, and sex

\begin{tabular}{|c|c|c|c|c|c|c|c|c|c|c|c|c|c|c|c|c|}
\hline & \multirow{2}{*}{\multicolumn{2}{|c|}{$\frac{13-17}{\text { Marriage }}$}} & \multicolumn{6}{|l|}{$0-4$} & \multirow{2}{*}{\multicolumn{2}{|c|}{$\frac{5-12}{\text { Enrolment }}$}} & \multirow{2}{*}{\multicolumn{2}{|c|}{$\frac{13-17}{\text { Primary }}$}} & \multirow{2}{*}{\multicolumn{2}{|c|}{$\begin{array}{l}5-17 \\
\text { Labour }\end{array}$}} & \multirow{2}{*}{\multicolumn{2}{|c|}{$\begin{array}{l}0-4 \\
\text { Bed net }\end{array}$}} \\
\hline & & & \multicolumn{2}{|c|}{ Stunting } & \multicolumn{2}{|c|}{ Underweight } & \multicolumn{2}{|c|}{ Wasting } & & & & & & & & \\
\hline & M & $\mathrm{F}$ & M & $\mathrm{F}$ & M & $\mathrm{F}$ & M & $\mathrm{F}$ & M & $\mathrm{F}$ & M & $\mathrm{F}$ & $\mathrm{M}$ & $\mathrm{F}$ & M & $\mathrm{F}$ \\
\hline National & 1.7 & 11.4 & 47.0 & 38.1 & 16.7 & 14.7 & 4.2 & 4.6 & 26.1 & 25.6 & 69.2 & 66.8 & 12.3 & 10.7 & 39.1 & 38.2 \\
\hline Rural & 1.8 & 14.1 & 50.1 & 40.6 & 18.6 & 16.2 & 4.3 & 5.2 & 30.0 & 29.9 & 80.3 & 80.3 & 15.4 & 13.7 & 43.2 & 42.3 \\
\hline Urban & 1.5 & 6.7 & 38.1 & 31.1 & 11.3 & 10.3 & 3.9 & 3.2 & 15.7 & 15.1 & 47.8 & 43.4 & 4.9 & 4.0 & 27.3 & 26.5 \\
\hline North & 1.6 & 13.9 & 54.3 & 45.5 & 21.3 & 18.0 & 6.4 & 6.8 & 38.9 & 36.9 & 81.7 & 82.9 & 14.1 & 11.7 & 34.6 & 31.4 \\
\hline Centre & 1.8 & 12.2 & 47.9 & 39.0 & 16.6 & 15.5 & 3.4 & 4.2 & 23.6 & 25.3 & 73.3 & 74.1 & 11.9 & 11.3 & 41.1 & 41.6 \\
\hline South & 1.6 & 7.3 & 30.0 & 21.6 & 7.8 & 6.0 & 2.2 & 1.6 & 8.3 & 6.9 & 47.3 & 37.7 & 10.3 & 7.9 & 42.5 & 42.3 \\
\hline
\end{tabular}

Source: Authors' calculations based on on 2014/15 Mozambican household budget survey data (IOF 2014/15) 


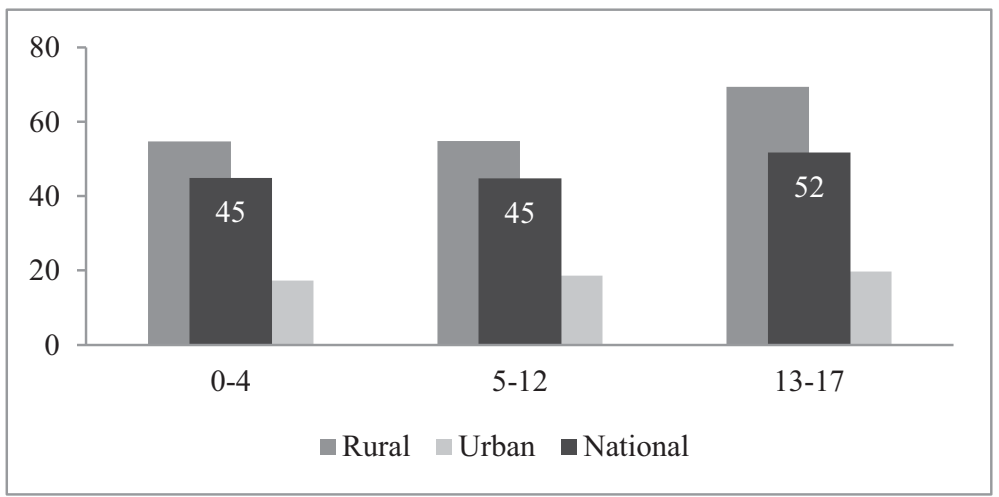

Fig. 4 Multidimensional poverty incidence by area and age group $(0-4 ; 5-12 ; 13-17)$. Source: Authors' calculations based on 2014/15 Mozambican household budget survey data (IOF 2014/15)

Table 11 Sensitivity of poverty incidence to poverty cut-offs $(k)$

\begin{tabular}{llllllll}
\hline$k$ & 0.2 & 0.3 & 0.4 & 0.5 & 0.6 & 0.7 & 0.8 \\
\hline National & 65.4 & 48.4 & 29.1 & 13.8 & 5.8 & 1.3 & 0.2 \\
Rural & 79.1 & 60.2 & 36.7 & 17.4 & 7.4 & 1.7 & 0.3 \\
Urban & 31.7 & 19.4 & 10.5 & 4.9 & 1.9 & 0.4 & 0.0 \\
North & 77.7 & 61.1 & 39.5 & 19.8 & 9.3 & 2.0 & 0.2 \\
Centre & 71.6 & 53.7 & 31.7 & 14.6 & 5.7 & 1.4 & 0.3 \\
South & 31.8 & 15.9 & 6.4 & 2.0 & 0.4 & 0.1 & 0.0 \\
\hline
\end{tabular}

The results presented in Sections 3.1 to 3.3 clearly show that estimates of multidimensional poverty based on the AF method can be greatly influenced by the indicators selected, the weights assigned to each indicator, and the cut-off $(k)$ used to define poverty. In Table 11, we show the poverty incidence in the case of the choice of different cut-offs $(k=0.2,0.3,0.4,0.5,0.6,0.7,0.8)$ at national and provincial level. We observe that, in general, the most relevant findings are confirmed; regional differences and regional rankings are essentially stable, regardless of the choice of $k$. The rural/urban and especially the north/south divides increase, with higher poverty cut-offs and lower national poverty rates, but only slightly. However, multidimensional poverty incidence is quite different in absolute values in the seven cases analysed because the greater the proportion of deprivation needed to consider a household as poor, the lower the poverty incidence. Hence, as expected, the poverty incidence levels are substantially lower in the case of $k>40 \%$ than in the other cases

Source: Authors' calculations based on 2014/15 Mozambican household budget survey data (IOF 2014/15) 
Table 12 Deprivation rates in $t_{2}$ by indicator and sex

\begin{tabular}{|c|c|c|c|c|c|c|c|c|c|c|}
\hline & \multicolumn{2}{|c|}{ Malawi } & \multicolumn{2}{|c|}{ Mozambique } & \multicolumn{2}{|c|}{ Tanzania } & \multicolumn{2}{|c|}{ Zambia } & \multicolumn{2}{|c|}{ Zimbabwe } \\
\hline & M & $\mathrm{F}$ & M & $\mathrm{F}$ & $\mathrm{M}$ & $\mathrm{F}$ & $\mathrm{M}$ & $\mathrm{F}$ & M & $\mathrm{F}$ \\
\hline Marriage & 1.7 & 11.4 & 3.8 & 26.9 & 1.4 & 12.7 & 0.5 & 7.2 & 2.6 & 13.2 \\
\hline Stunting & 39.8 & 35.5 & 45.2 & 40.8 & 36.7 & 32.1 & 42.4 & 37.7 & 29.5 & 23.9 \\
\hline Underweight & 12.7 & 10.4 & 16.9 & 13.4 & 13.8 & 13.0 & 15.9 & 13.6 & 8.3 & 8.0 \\
\hline Wasting & 3.3 & 2.1 & 6.5 & 5.5 & 5.2 & 3.8 & 6.2 & 5.8 & 3.3 & 3.1 \\
\hline Enrolment & 5.3 & 4.0 & 25.2 & 25.1 & 21.7 & 17.5 & 24.3 & 20.8 & 4.2 & 2.5 \\
\hline Primary & 70.3 & 66.5 & 71.8 & 70.0 & 51.4 & 40.8 & 57.9 & 51.6 & 33.4 & 23.1 \\
\hline Bed net & 50.1 & 49.9 & 61.0 & 61.2 & 39.9 & 39.4 & 57.1 & 56.9 & 88.3 & 88.8 \\
\hline
\end{tabular}

The Mozambican child marriage rate for girls is $27 \%$ in 2011 , which is more than double the $12 \%$ 2014/15 IOF value that is reported in Table 10. However, the IOF rate for girls in a comparable age range, 15-17, is $20 \%$. The remaining 7-percentage-point difference is likely due to the inclusion of informal unions or 'living together' in the DHS marriage variable, which is not clearly specified in the IOF questionnaire. In the 2003 DHS, $20 \%$ of girls in this age range are classified as 'living together' with a partner. This figure is substantially lower in other countries (2, 2, 0.2, and 0.3 in Malawi, Tanzania, Zambia, and Zimbabwe, respectively). Though informal unions are also included in later-year DHS classifications, they are grouped together with formal unions. This distinction appears to be an important consideration when evaluating child marriage rates in Mozambique. Boys are more deprived in both primary school enrolment for children aged 5-12 and primary school completion for children aged 13-17. This is most striking for children in Tanzania, where the gap is 4 points in enrolment and more than 10 points in primary completion. Mozambique stands out as having relatively little gender difference at the national level in either indicator. However, as discussed in Section 3.2, gender educational gaps do indeed occur in Mozambique, where boys are less deprived in the central region and more deprived in the south

Source: Authors' calculations based on the 2004 and 2015 DHS for Malawi; the 2003 and 2011 DHS for Mozambique; the 2004 and 2015 DHS for Tanzania; the 2007 and 2013 DHS for Zambia; and the 2005 and 2015 DHS for Zimbabwe (DHS 2017)

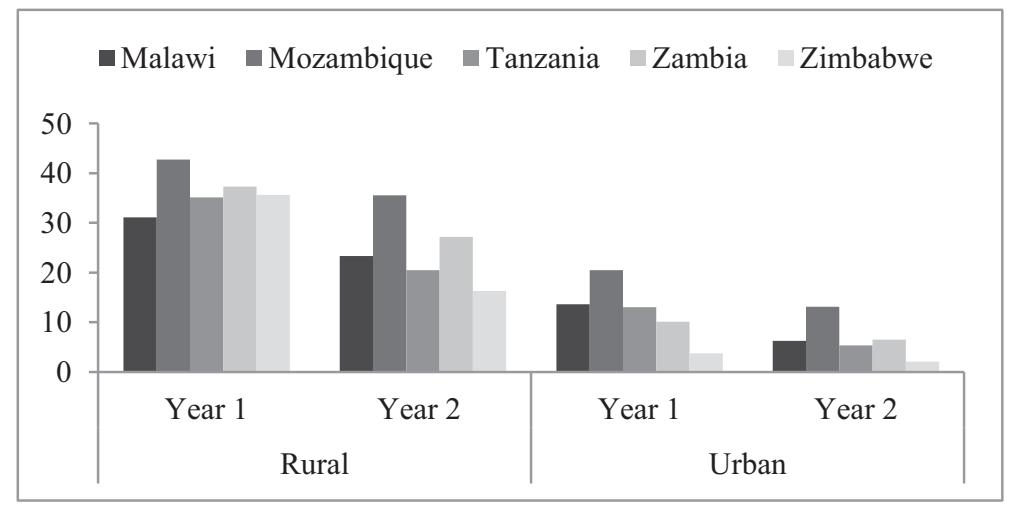

Fig. 5 Rural and urban poverty index $\left(M_{0}\right)$ by survey year. Source: Authors' calculations based on the 2004 and 2015 DHS for Malawi; the 2003 and 2011 DHS for Mozambique; the 2004 and 2015 DHS for Tanzania; the 2007 and 2013 DHS for Zambia; and the 2005 and 2015 DHS for Zimbabwe (DHS 2017) 


\section{References}

Alkire, S., \& J. Foster (2007). Counting and multidimensional poverty measurement. OPHI (Oxford Poverty and Human Development Initiative) working paper 7. Oxford: OPHI, University of Oxford.

Alkire, S., \& Foster, J. (2011). Understandings and misunderstandings of multidimensional poverty measurement. The Journal of Economic Inequality, 9(2), 289-314.

Alkire S., \& G. Robles (2016). Global multidimensional poverty index 2016. OPHI Briefing 40. Oxford: OPHI, University of Oxford.

Alkire, S., \& M. Santos (2010). Acute multidimensional poverty: A new index for developing countries. OPHI working paper 38. Oxford: OPHI, University of Oxford.

Alkire, S., Foster, J., Seth, S., Santos, M., Roche, J., \& Ballon, P. (2015). Multidimensional poverty measurement and analysis. Oxford: Oxford University Press.

Alkire, S., Jindra, C., Robles G., \& Vaz A. (2017). Children's multidimensional poverty: Disaggregating the global MPI. OPHI Briefing 46. Oxford: OPHI, University of Oxford.

Arndt, C., Distante, R., Hussain, M. A., Østerdal, L. P., Huong, P., \& Ibraimo, M. (2012). Ordinal welfare comparisons with multiple discrete indicators: A first order dominance approach and application to child poverty. World Development, 40(11), 2290-2301.

Arndt, C., Jones, E. S., \& Tarp, F. (2016). Mozambique: Off-track or temporarily sidelined? In C. Arndt, A. McKay, \& F. Tarp (Eds.), Growth and poverty in sub-Saharan Africa. Oxford: Oxford University Press.

Arndt, C., F. Castigo, M. Ibraimo, S. Jones, K. Mahrt, V. Salvucci, R. Santos, \& F. Tarp (2017), Evolução da Pobreza e Bem-Estar em Moçambique, 1996/97-2014/15. Inclusive Growth Mozambique Working Paper 2017. Available at: http://igmozambique.wider.unu.edu/pt/article/evolu\%C3\%A7\%C3\%A3o-da-pobrezae-bem-estar-em-mo\%C3\%A7ambique. Accessed 05 February 2020.

Azzarri, C., Carletto, G., Davis, B. \& Nucifora, A., 2011. Child undernutrition in Mozambique. Unicef and The World Bank, mimeo.

Baez Ramirez, J.E., G.D. Caruso, C. Niu, \& C.A. Myers (2018). Mozambique poverty assessment: Strong but not broadly shared growth: Overview. Washington, D.C.: World Bank Group. http://documents. worldbank.org/curated/en/377881540320229995/Overview (Accessed 08 October 2019).

Cardoso, J., L. Allwright, \& V. Salvucci (2016a). Characteristics and determinants of child malnutrition in Mozambique, 2003-11. WIDER working paper 147. Helsinki: UNU-WIDER.

Cardoso, J., J. Morgado \& V. Salvucci (2016b). Mapping Deprivation in Mozambique: An Analysis of Census Data (1997-2007). WIDER working paper 166. Helsinki: UNU-WIDER.

Castigo, F., \& V. Salvucci (2017). Estimativas e Perfil da Pobreza em Moçambique, Inclusive Growth Mozambique Working Paper 2017. Available at: http://igmozambique.wider.unu. edu/pt/article/estimativas-e-perfil-da-pobreza-em-mo\%C3\%A7ambique-uma-analise-baseada-noinqu\%C3\%A9rito-sobre (Accessed 08 October 2019).

de Milliano, M., \& Plavgo, I. (2018). Analysing multidimensional child poverty in sub-Saharan Africa: Findings using an international comparative approach. Child Indicators Research, 11(3), 805-833.

DEEF (Ministry of Economics and Finance). (2016). Pobreza e Bem-Estar em Moçambique: Quarta Avaliação Nacional. Maputo: DEEF.

DHS (2017). The DHS Program Demographic and Health Surveys: Available Datasets. Available at: http://www.dhsprogram.com/data/available-datasets.cfm (Accessed 19 April 2017).

DNPO. (2004). Poverty and wellbeing in Mozambique: Second national poverty assessment. Maputo: DNPO.

DNPO (Ministry of Planning and Finance). (1998). Understanding poverty and wellbeing in Mozambique: The first national assessment, 1996-97. Maputo: DNPO.

EPRS. (2018). Child marriages: Still too many. Brussels: European Parliamentary Research Service.

Ferrone, L., Rossi, A., \& Brukauf, Z. (2019). Child poverty in Mozambique - Multiple overlapping deprivation analysis (pp. 2019-2003). Florence: Office of Research - Innocenti Working Paper WP.

Ibraimo, M. \& V. Salvucci (2017). Os Determinantes da Pobreza em Moçambique, 2014/15, Inclusive Growth Mozambique Working Paper 2017. Available at: http://igmozambique.wider.unu.edu/pt/article/osdeterminantes-da-pobreza-em-mo\%C3\%A7ambique-201415 (Accessed 11 October 2019).

INE (Instituto Nacional de Estatística). (2015). Relatório Final do Inquérito ao Orçamento Familiar - IOF2014/15. Maputo: INE.

INS (Instituto Nacional de Saúde) \& ICF International. (2019). Inquérito Nacional sobre Indicadores de Malária em Moçambique 2018. Maputo; Rockville: INS and ICF International.

Jain, S., \& Kurz, K. (2007). New insights on preventing child marriage: A global analysis of factors and programs. Washington: International Center for Research on Women (ICRW). 
Khan, N.U.Z., S. Rasheed, T. Sharmin, A.K. Siddique, M. Dibley \& A. Alam (2018). How can mobile phones be used to improve nutrition service delivery in rural Bangladesh?. BMC health services research, 18/530.

Mahdi, S., A.C. Allen, F.A.P. Massarongo, J.E. Baez Ramirez, I.D. Walker, A.N. Mucavele Macule, R.J. De Lemos Botelho Barreto \& J. Casal (2018), Mozambique economic update: Shifting to more inclusive growth. Washington, D.C.: World Bank Group. Available at: http://documents.worldbank. org/curated/en/132691540307793162/Mozambique-Economic-Update-Shifting-to-More-InclusiveGrowth (Accessed 8 October 2019).

MISAU (Ministry of Health), INE, \& ICF International. (2013). Moçambique Inquérito Demográfico e de Saúde 2011. Calverton: ICF International.

MISAU (Ministry of Health), INE, \& ICF International. (2016). Inquérito de Indicadores de Imunização, Malária e HIV/SIDA em Moçambique (IMASIDA) 2015 - Relatório de Indicadores Básicos. Maputo; Rockville: INS, INE and ICF International.

MPD (Ministry of Planning and Development) \& DNEAP (National Directorate for Studies and Policy Analysis). (2010). Poverty and wellbeing in Mozambique: Third National Poverty Assessment. Maputo: MPD/DNEAP.

OPHI (2017). Mozambique country briefing, multidimensional poverty index data bank. Oxford: OPHI, University of Oxford. Available at: http://www.dataforall.org/dashboard/ophi/index.php/mpi/country_ briefings (Accessed 31 July 2018).

Pomati, M., \& Nandy, S. (2019). Assessing Progress towards SDG2: Trends and patterns of multiple malnutrition in young children under 5 in west and Central Africa. Child Indicators Research, 1-27.

Sahn, D. E., \& Alderman, H. (1997). On the determinants of nutrition in Mozambique: The importance of agespecific effects. World Development, 25(4), 577-588.

Salvucci, V. (2016). Determinants and trends of socioeconomic inequality in child malnutrition: The case of Mozambique, 1996-2011. Journal of International Development, 28(6), 857-875.

Save the Children. (2016). Child poverty: What drives it and what it means to children across the world. London: Save the Children.

Sekabira, H., \& Qaim, M. (2017). Can mobile phones improve gender equality and nutrition? Panel data evidence from farm households in Uganda. Food Policy, 73, 95-103.

UNDP (2018). Human development indices and indicators: 2018 statistical update. New York: UNDP. Available at: http:/hdr.undp.org/sites/default/files/hdr2018_ technical_notes.pdf (Accessed 03 October 2019).

UNDP and OPHI (2019). Global multidimensional poverty index 2019 - illuminating inequalities. UNDP and OPHI.

UNFPA. (2012). Marrying too young - end child marriage. New York: UNFPA.

UNICEF. (2006). Childhood poverty in Mozambique: A situation and trends analysis. Maputo: UNICEF.

UNICEF. (2011). Child poverty and disparities in Mozambique. Maputo: UNICEF.

UNICEF (2013). Impact of unpaid household services on the measurement of child labour. MICS (Multiple Indicator Cluster Surveys) methodological paper 2. New York: UNICEF.

UNICEF. (2014). Situation analysis of children in Mozambique 2014. Maputo: UNICEF.

UNICEF \& UNFPA. (2018). Key drivers of the changing prevalence of child marriage in three countries in South Asia. New York: UNICEF and UNFPA.

UNICEF/WHO/World Bank. (2017). Levels and trends in child malnutrition - key findings of the (2017th ed.). UNICEF/WHO/World Bank.

UN-Mozambique. (2016). United Nations agenda for the reduction of chronic Undernutrition in Mozambique. Maputo: United Nations-Mozambique.

Publisher's Note Springer Nature remains neutral with regard to jurisdictional claims in published maps and institutional affiliations. 